University of Wollongong

Research Online

Faculty of Social Sciences - Papers (Archive) Faculty of Arts, Social Sciences \& Humanities

2015

Measuring the quality of movement-play in Early Childhood Education settings: Linking movement-play and neuroscience

Carol Archer

Camden Integrated Early Years Service

Iram Siraj-Blatchford

University of Wollongong, iram@uow.edu.au

Follow this and additional works at: https://ro.uow.edu.au/sspapers

Part of the Education Commons, and the Social and Behavioral Sciences Commons

Research Online is the open access institutional repository for the University of Wollongong. For further information contact the UOW Library: research-pubs@uow.edu.au 


\title{
Measuring the quality of movement-play in Early Childhood Education settings: Linking movement-play and neuroscience
}

\author{
Abstract \\ This article explores the links between neuroscience research, movement, and neurological dysfunction in \\ relation to young children's learning and development. While policymakers have recognised the \\ importance of early development the role of movement has been overlooked. A small scale study was \\ undertaken in four early years settings in a London Borough in order to investigate whether an \\ intervention resulted in improved movement experiences for children. This is the first study to assess the \\ quality of movement-play using a newly developed measuring scale. Results showed that an intervention \\ does result in improved movement experiences for young children. Consistently enhanced results were \\ found in relation to the vital role of the adult at the two intervention settings. For Vygotsky the adult role is \\ critical to the quality of play and learning for the child (Siraj-Blatchford 2009). There is scope for a larger \\ scale piece of research spread across different sectors in order to further test the validity and reliability of \\ the scale.

\section{Keywords} \\ linking, childhood, education, measuring, quality, movement, play, settings, early, neuroscience

\section{Disciplines} \\ Education | Social and Behavioral Sciences

\section{Publication Details} \\ Archer, C. \& Siraj, I. (2015). Measuring the quality of movement-play in Early Childhood Education settings: \\ Linking movement-play and neuroscience. European Early Childhood Education Research Journal, 23 (1), \\ 21-42.
}




\title{
Measuring the quality of movement-play in Early Childhood Education settings:
}

\section{Linking movement-play and neuroscience}

Carol Archer a* and Iram Siraj b*

aCamden Integrated Early Years Service, Children Schools and Families, London Borough of Camden, London, UK; bEarly Years and Primary Education, Institute of Education University of London, London, UK

*Corresponding author. Email: carol.archer@camden.gov.uk

\begin{abstract}
This paper explores the links between neuroscience research, movement, and neurological dysfunction in relation to young children's learning and development. While policy makers have recognised the importance of early development the role of movement has been overlooked. A small scale study was undertaken in four early years settings in a London Borough in order to investigate whether an intervention resulted in improved movement experiences for children. This is the first study to assess the quality of movement-play using a newly developed measuring tool. Results showed that an intervention does result in improved movement experiences for young children. Consistently enhanced results were found in relation to the vital role of the adult at the two intervention settings. For Vygotsky the adult role is critical to the quality of play and learning for the child (Siraj-Blatchford, 2009). There is scope for a larger scale piece of research spread across different sectors in order to further test the validity and reliability of the scale.
\end{abstract}

Key words: neuroscience, neurological reorganisation, movement-play, quality, intervention, young children 


\section{Introduction}

Neuroscientists (Cotman 2007; Hillman 2008; O’Callaghan, Ohlem, and Kelly 2007; O’Callaghan, Griffin, and Kelly 2009) exploring the links between neuroscience and brain development have investigated how exercise effects brain function. Practitioners in the field of neurological dysfunction and reorganisation (Goddard Blythe 2007; Lamont 2007a) consider the relationship between specific movement patterns and neurological development stressing their influence on later academic achievement.

Against the backdrop of this on-going discourse, this study has investigated if an intervention, consisting of an in-service training and follow-up support, did result in improved movement experiences for children in early childhood settings.

Three principal research questions shaped this investigation:

1) Does an intervention result in improved movement experiences for children?

2) What is the quality of the environment and practice of movement play before and after an intervention?

3) What is the link between neuroscience and brain development and how can movement influence children’s development and learning?

In order to assess the quality of provision and practice in relation to children's movement a scale was developed which was modelled on the Early Childhood Environmental Rating Scale Extension (ECERS-E) (Sylva et al 2006a). The scale is in appendix 1 and readers are welcome to photocopy for their use. The authors would be delighted to hear from readers about their results.

This movement-play scale has three items:

Item 1 Space and resources

Item 2 Adults engaging in movement with children 
Item 3 Planning for movement-play from observations of children

At the time of undertaking this research no such measure was available to assess the quality of movement-play.

\section{Literature Review}

Neuroscience studies (Cotman, Berchtold, and Christie 2007; Hillman, Erickson, and Kramer 2008; O’Callaghan, Ohlem, and Kelly 2007; O’Callaghan, Griffin, and Kelly 2009; van Praag 2009) have begun to shed light on the brain and learning. New scientific insights have the potential to help us understand teaching and learning in new ways. For example neuroscientists have demonstrated the benefits of exercise on brain function (Cotman et al. 2007; Hillman et al. 2008; O’Callaghan et al. 2007; O’Callaghan et al. 2009; van Praag 2009).

Neuroscientific research on animals show that exercise enhances and supports brain function more specifically cognitive function, enhancing learning and memory (O’Callaghan et al. 2007; O’Callaghan et al. 2009). Findings related to brain function in youth indicate that exercise early in a person's life can contribute to the improvement of cognitive function during childhood and may improve their academic performance (Hillman et al 2008). van Prag (2008) suggests that aerobic exercise in childhood might increase the resilience to brain neurological damage later in life. Indeed exercise on a regular basis has been found to alter brain functions that underlie cognition and behaviour. Exercise has also been shown to reduce risk factors related to health such as obesity, diabetes and cardiovascular disease (van Prag 2008; Cotman et al 2007). van Prag further suggests that exercise and a healthy diet also provide substantial benefits for brain function. Evidence is thus growing to show the link between neuroscience and brain development. 
However, most studies have been conducted on animals in a lab with just a few studies relating to exercise and cognition carried out mostly on older children and young adults. Is it possible, therefore, from the knowledge gained about animals and mostly youth to apply this to very young children, particularly those aged from birth to five? And how should results be interpreted and implemented into educational programmes for younger children?

There is no clear consensus amongst neuroscientists (Blakemore and Frith 2005; Bruer 2002; Howard-Jones 2007) about the implications of brain science for education.

For example, Bruer, (2002, 1032), focusing on peak synaptic densities linked to critical times for learning, is sceptical that neuroscience research has much to offer teachers, arguing that its application to education has 'little practical value' right now advocating more years of research for this 'approach to bear fruit'. Recently, HowardJones (2007, 8), investigated the number of ‘educational neuromyths’ arising, and called for more interdisciplinary cooperation between educators, policymakers and neuroscientists for 'scientific validity and educational relevance'. Blakemore and Frith $(2005,459)$ stress the importance of anchoring education in neuroscientific evidence based research highlighting that 'now is the time to explore the implications of brain science for education'. Research on the brain and learning they believe 'could influence the way we think about teaching' which could 'transform educational strategies and enable us to design educational programmes that optimise learning' (Blakemore and Frith 2005, 460). However, there is no clear academic consensus on this matter (Blakemore and Frith 2005; Bruer 2002; Howard-Jones 2007). Practitioners and researchers working in the field of neurological dysfunction and reorganisation (Goddard Blythe 2007; Lamont 2007a) are however, persuaded by the 
influence that specific movement patterns have on the neurological system and the brain and argue for its critical application to education. For instance in her work with children as a Developmental Movement Therapist, Lamont (2007b) argues that when children repeat movement patterns specific areas of their brain are stimulated.

Conversely when babies miss out on significant movements such as belly crawling or crawling, critical functions are compromised affecting later development and thus their ability to reach their full potential at school (Lamont 2007c).

Goddard Blythe (2005) has developed a programme of physical exercises based on movements children normally make in the first year of life and has evidence to show enhanced literacy skills of children who have participated in these daily physical exercises at school.

Goddard Blythe, (2005a) also questions whether every child is ready for school in terms of their neuromotor development which describes a range of physical skills including balance, posture and coordination. If these physical foundations for learning are secured in the pre-school years, then the child enters the school system better equipped to cope with the demands of the classroom, such as the ability to sit and concentrate, coordinate the hand and eyes when writing, control the eye movements needed for reading. Some children appear to be more ready than others when starting school. One way of addressing this situation would be to ensure that all infants and young children are provided with opportunities for movement-play activities which stimulate and train the balance mechanism, posture and coordination of the body. Maude (2006, 251) suggests that children become increasingly 'physically literate' through movement experiences in their early years. Nonetheless children need to experience a varied and worthwhile movement vocabulary in order to broaden their physical literacy. To achieve this Maude (2006) proposes a relevant and 
effective physical education curriculum which cultivates skilful, articulate and creative movement in children in which the role of the educator is central.

This can be achieved in terms of how environments are organised, what resources are provided, and the interactions between adults and children and children to children.

\section{Measuring quality}

It is important to distinguish between different aspects of quality, because scholars such as Dahlberg et al $(1999,166)$ have argued that perspectives of quality are not universally accepted, are varied and have 'inherently subjective and productive understandings of childhood'. Indeed Munton, Mooney, and Rowlands' (1995) refer to six dimensions of quality: effectiveness, acceptability, efficiency, access, equity and relevance. Further study is required to analyse quality in relation to its effectiveness in enhancing children's experiences in movement-play. The focus of this study is the evaluation of the intervention and measuring quality in relation to the environment and pedagogy.

Research has shown that high quality care is associated with improved developmental outcomes for children and conversely lower quality to poorer outcomes (Belsky, 2001; Peisner-Feinberg et al. 2000; Sylva et al. 2006a). Some go as far to say that children from disadvantaged backgrounds are considered to be the most affected by the level of quality of care (McCartney et al 2007).

The relationship between quality environments and children's outcomes suggests that it is important to use a valid tool to assess and improve quality. Quality may be considered in terms of environments, curricular and pedagogy. The Early Childhood Environmental Rating Scale-Revised (ECERS-R) (Harms, Clifford, and Cryer 2005) 
is used to assess and improve quality of provision and practice and many studies indicate its predictions on children's development are accurate (Mathers et al 2007).

ECERS-Extension (Sylva et al 2006b), was used specifically for assessing curricular aspects of quality, including pedagogy. It was used in pre-school centres in the longitudinal study, Effective Provision of Pre-school Education (EPPE) (Sylva et al 2004). When compared, the ECERS-R is more sensitive to quality related to children's social-behavioural development, while ECERS-E is more sensitive to children’s cognitive progress and their academic skills (Sylva et al 2006a). SirajBlatchford and Wong $(1999,11)$ point out that while 'quality may in part be subjective it should not be arbitrary'. The movement-play items, modelled on ECERS-E format, were therefore an attempt to develop a measure which provided an informed objective assessment of quality.

Acknowledging that a combination of qualitative and quantitative methods is useful to gain a more completed picture this research also involved the use of 'unstructured interviews’ (Robert-Holmes 2011, 5). This approach enabled 'conversations with a purpose' (Siraj-Blatchford 2010, 225) to take place during the four follow-up sessions of support and advice at the intervention settings.

\section{Design}

The main study involved a mixed methods research design and included a naturalistic quasi-experiment in two intervention and two comparison settings.

\section{The movement-play scale}

The development of the movement-play scale involved undertaking a pilot study in order to trial the items to assess how well they worked, how reliable they were and from this to ascertain what adaptations need to be made for its use in this study. Amendments were subsequently made to the scale so that it was ready for use. 
The final copy of the movement-play scale (see appendices) used in this study includes three items: Item 1 Space and Resources; Item 2 Adult engaging in movement with children: Item 3 Planning for movement-play from observations of children. Each item is accompanied by extensive notes for clarification.

\section{Methods of data collection}

This study was predisposed to a largely quantitative methodological design involving the development and use of a measurement scale pre- and post-intervention.

In addition qualitative approaches were employed, which sought practitioner and managers views through the use of unstructured interviews to elicit their perspectives on the implementation of movement-play.

\section{Validity and Reliability}

This less structured approach results in greater validity since the researcher finds out more as the purposeful conversation takes place thus capturing important features in this study which were analysed with integrity. This may be at the expense of reliability though compared to more structured interviews employing quantitative data (Siraj-Blatchford 2010, 225). It was therefore intended that scores from the scale could provide more objective data to facilitate maximum reliability. Robson (2002) suggests that adding a pre-test/post test design is advantageous because the data would help us to counter threats to internal validity.

The use of this scale was, at the time, limited to a pilot study as well as its application to this small scale research. The scale was piloted with settings that were familiar with ECERS and had received training in movement-play. Twelve practitioners from a Children's Centre, five private nurseries, one specialist nursery and one nursery class administered the scale. 
The findings indicated that $80 \%$ of participants found all the items 'easy' to use and 'useful' for measuring quality. The items also showed 'progression' thus guiding practitioners in ways to improve their environment and practice. Participants who responded negatively had not used ECERS before which may have accounted for their difficulty since the head selected practitioners to administer the scale who were new to the tool though familiar with movement-play. Further remarks indicated that it provided a 'common language' for professionals to use with the aim of improving movement experiences for children.

A large scale research study would be needed to demonstrate that quality as measured by this scale has validity and to test the reliability of the indicators.

Notwithstanding the need for a larger scale research study, this scale provided a measure with a predetermined structure which was repeatedly applied to each setting. This structure affords greater reliability than less structured research instruments such as observational coding schemes (Siraj-Blatchford 2010). This quantitative approach to data collection provided objectivity allowing for generalisations to be made to larger populations.

Bias in the results may arise from the study sample for instance in terms of socioeconomic characteristics and cultural background. However, the lack of this type of data in this study means that it cannot guarantee external validity and generality despite the attempt to mitigate this and describe carefully the selection process and nature of the sample study. The findings should therefore be interpreted with some caution.

Threats to internal validity cannot necessarily be ruled out in this study; for example changes in practices by participants may have been unrelated to the intervention (Robson 2002, 105). However, although internal validity cannot be 
guaranteed an honest attempt was made to ensure that the intervention was measured accurately.

Triangulation was attempted in order to build a fuller picture: data obtained from the use of the scale, evaluations and informal conversations attempted to accomplish data triangulation; methodological triangulation was achieved through the use of multiple methods described through both quantitative and qualitative approaches.

\section{Sample}

Settings were selected from private and voluntary sectors and Children's Centres in an area of London which had not had any previous input on movement-play and were able to allocate a whole day in-service training.

These requirements limited the number of settings which could potentially be invited to participate because movement-play has been implemented in many of this area's Early Years settings over the last six years. Moreover, it was important to select similar settings in terms of size and age groups in order to be able to carry out a useful comparative analysis. Therefore all settings considered for selection included children aged from four months to five years. The Early Years Advisors with responsibility for supporting the settings decided on which ones should receive the intervention and which should be the comparison settings. Managers of the settings were approached for their consent to be involved in the study. All settings agreed which role would suit them best, and thus not all settings received training at the time the research was carried out. In order that settings felt comfortable with their involvement, and the research ethical, training was offered to the comparison settings on a date after completion of the study. 
Participants were thus chosen using convenience sampling. It is not possible to know whether or not findings using this method are representative (Robson 2002, 265) compared to larger investigations over longer periods of time which involve random sampling. The size, timing and sampling method used were the only options in terms of manageability in undertaking this study. Nonetheless, Blaise $(2010,210)$ suggests that small scale studies are not necessarily 'smaller or less important versions of larger investigations' they are 'just different'.

Thus quantitative and qualitative approaches in non-equivalent groups were used. It was not possible in this small scale study to find equivalent groups prior to the intervention, and therefore settings were selected on a 'best fit' basis. Accordingly, all four settings selected are in the private sector with rooms for babies, toddlers and preschool. The numbers of babies in each setting ranged from six to nine; and 12 to 16 toddlers; and 16 to 24 pre-school children.

\section{Data Collection Procedures}

The scale was administered at the first intervention setting in the same week as the comparison setting. Scores for each item were recorded and clarification was provided where necessary. The same process was followed with the second intervention and comparison settings a month later.

After the training, the intervention settings agreed on dates for four follow-up support and advice sessions. At each of these visits the room leaders, practitioners and managers were informally interviewed for feedback on successes and challenges.

At the end of the four week period the movement-play sub-scale was administered in each of the rooms at the intervention and comparison settings for the second time. Meetings were held to feedback findings to the intervention settings. 
Both pre and post-tests were administered in all four settings to enable a comparative analysis.

\section{Ethical Issues}

The research adhered to the Revised Ethical Guideline for Educational Research on BERA (2004) website; and kept in mind the relevant ethical considerations found in Robson (2002, 65-71). Ethical considerations relating to a good intervention included consideration given to the selection of settings; their choice to take part or not; unrestricted choice to withdraw at any time; being fully informed of what was involved; and confidentiality of names of settings taking part. All of which are important when working with children.

One researcher was responsible for administering the subscale in the four private settings while co-author acted as a critical friend scrutinising data collected from all rooms at each setting. The findings were discussed and critiqued by an independent critical 'friend’ (early years specialist) and local authority staff.

\section{The intervention}

Following administration of the scale, training was delivered followed by four sessions of advice and support.

The intervention included one day's training in movement-play for all staff including managers and deputies at each of the intervention settings. The training included practical work when staff would be asked to take part in movement activities followed by explanations of the benefits for children in terms of stimulation to the neurological system and learning and development. During the second-half of the training participants discussed and planned how they would implement movementplay in their respective rooms. 
Evaluations of the training revealed that all participants 'strongly agreed' or 'agreed' that the course was useful in meeting their needs except one who was undecided and that they felt confident to put into place what they had learned. Participants commented positively about the 'activities' undertaken during the course, 'using the resources', 'understanding the importance of moving' and 'realising that physical play has significance to learning'.

Research (Siraj-Blatchford et al. 2002) shows that practitioner knowledge and understanding of the particular curriculum area that is being addressed is vital. Early years practitioners need to have a 'good grasp' of 'pedagogical content knowledge' in order to be 'effective educators’ of young children (Sylva et al 2004, 38). Evangelou et al (2009 5) remind us that 'Enhancing children’s development is skilful work and practitioners need training and professional support to do it well'.

Below is a brief outline of observations made during follow-up visits when advice and support through modelling and coaching were offered and discussions took place about successes and constraints of implementation.

\section{Baby Rooms}

The baby rooms at both interventions settings were organised in a safe and creative way for babies to explore their bodies as they used a variety of resources. Intervention setting 1 provided soft balls, large body balls, a rocker, rocking horse, pillows and lycra. More practitioners joined the babies in movement after the training compared to previous observations when only the room leader did so.

At the second intervention setting babies were provided with opportunities for floor play and other movement-play activities such as rocking babies in the lycra, pulling a baby along the floor whilst lying on gold lame material, crawling through a tunnel, climbing over, up and down soft play shapes, climbing and sliding on the baby 
gym. One practitioner commented that she and the babies enjoyed their movement time together. Advice was given about laying the babies on their tummies to encourage them to become mobile. Opportunities were provided for babies to continue these activities outside by taking out specific resources each day but the range was limited and no activities were vigorous at both intervention settings.

\section{Toddlers}

The lead practitioner at the second intervention setting commented during my first visit that they had had a 'wonderful' morning, that the room was more 'interesting' and the children 'really enjoyed' the movement activities. A dedicated space was now provided for movement-play with at least seven pieces of equipment. Adults sometimes joined toddlers indoors and outdoors whilst they were spinning, crawling, rolling, climbing, sliding, tug of war, and dancing. One practitioner commented that the movement activities had 'energised' both the staff and the children; and children ‘seek out every activity they can’; children are ‘bonding a lot more together as friends'; her bond with them is 'stronger'. Another said that when moving on the floor with the children she saw things 'from their point of view'.

Initially staff at the first intervention setting implemented activities for the whole group but gradually over the four weeks they organised their room and resources so that children were able to move freely in and out of the movement activities provided.

\section{Pre-school}

Movement resources such as a spinning cone, mats, lycra, soft play shapes, small softy balls, large elastic and ribbon sticks had been set up at the second intervention setting. Small group of children joined the practitioner in movement activities such as spinning, rolling, tug of war, jumping, tummy crawling, and dancing using these 
resources for two half-hour sessions each day. She said that 'children chat to each other a lot more' during movement-play activities and that they 'really like having small group time', and ask to go into the movement room. Children were engaging in much more adventurous play outdoors since movement activities have been implemented indoors.

At intervention setting 1 soft play shapes, mats and a climbing frame provided children with opportunities for vigorous activities indoors. The environment encouraged socialisation between children with movement conversations as well as verbal communication: 'I’m going to jump right over there'; children reorganised the resources: 'Lets move the mats'; they told each other how they felt: 'I don't like the noise'. Mats and cushions enabled children to roll around, jump and rough and tumble together.

\section{Results}

The table below represents pre-test and post-test scores for each scale item for all rooms at the intervention and comparison settings.

Table 1 Score: 1 = inadequate; 3 = minimal; 5 = good; 7 = excellent.

\begin{tabular}{|l|l|l|l|l|l|l|l|l|l|l|l|l|}
\hline \multirow{4}{*}{ Items: } & \multicolumn{4}{|c|}{$\begin{array}{l}\text { 1: Space \& } \\
\text { resources }\end{array}$} & \multicolumn{4}{c|}{$\begin{array}{l}\text { 2: Adults engaging } \\
\text { in movement }\end{array}$} & \multicolumn{3}{|c|}{$\begin{array}{l}\text { 3: Planning from } \\
\text { observations }\end{array}$} \\
\hline Babies & I1 & I2 & C1 & C2 & I1 & I2 & C1 & C2 & I1 & I2 & C1 & C2 \\
\hline Pre-test results & 4 & 4 & 4 & 4 & 2 & 3 & 2 & 3 & 4 & 2 & 4 & 4 \\
\hline Post-test results & 4 & 5 & 4 & 4 & 4 & 4 & 2 & 3 & 4 & 3 & 4 & 4 \\
\hline Toddlers & I1 & I2 & C1 & C2 & I1 & I2 & C1 & C2 & I1 & I2 & C1 & C2 \\
\hline Pre-test results & 4 & 4 & 3 & 2 & 2 & 2 & 2 & 2 & 4 & 2 & 4 & 3 \\
\hline Post-test results & 4 & 6 & 3 & 3 & 4 & 4 & 2 & 2 & 4 & 4 & 4 & 3 \\
\hline Pre-school & I1 & I2 & C1 & C2 & I1 & I2 & C1 & C2 & I1 & I2 & C1 & C2 \\
\hline Pre-test results & 4 & 3 & 3 & 3 & 3 & 2 & 2 & 2 & 3 & 3 & 3 & 3 \\
\hline Post-test results & 4 & 3 & 3 & 3 & 4 & 4 & 2 & 2 & 3 & 3 & 3 & 3 \\
\hline
\end{tabular}

I1 = Intervention setting 1; I2 = Intervention setting 2

C1 $=$ Comparison setting 1; C2 = Comparison setting 2 
In Table 1 results for Item 1, space and resources, show that the toddler room and baby room at setting 2 increased their scores from 4 to 6 (above good) and 5 (good) respectively. The toddler room increased their score after the intervention because more resources were set up each day encouraging toddlers to move in a variety of ways including challenging activities.

However, children at setting 1 were engaged in challenging activities indoors but not outdoors and therefore not able to fulfil indicator 5.3 thus scoring 4 for item 1 .

\section{Item 2}

All rooms at both the comparison and intervention settings scored minimal or below in this item prior to the intervention. These scores did not change during the course of the study at the comparison setting.

These results appeared to reflect practitioners adopting a non-interactive observational approach. Comments made by practitioners in response to questions about joining children in their movement-play included 'adults don't join babies in their movement-play'; other practitioners responded with 'I observe', and 'I make sure they are safe' and 'We create the space for movement and the adults stand in specific areas’ observing children in their play outdoors.

Contrastingly the intervention settings increased their score for this item from minimal and below to 4, above minimal after training and follow-up support and advice. The post-test results indicate that the majority of adults at the intervention settings were encouraging (3.2) and prompting and joining (5.1) children in their movement activities after the intervention. This suggests that most adults were adopting a more interactive role in their engagement with children post intervention including vigorous activities indoors for toddlers and pre-school children but not necessarily outdoors. 


\section{Item 3}

Results for intervention setting 1 and both comparison settings remained the same over the period of the study.

The Toddler Room at the second intervention setting increased their score from below minimal to 4 above minimal after training and support. Staff were recording observations of movement activities for individual children and planning for their specific needs and interests. After implementing movement-play activities in their room staff noticed that behaviour had changed for all children. The Baby Room increased their score from 2 to 3 whilst the Pre-school results remained the same.

\section{Figure 1}

The graph below represents the mean scores for pre-test and post-tests for each age group at the intervention and comparison settings.

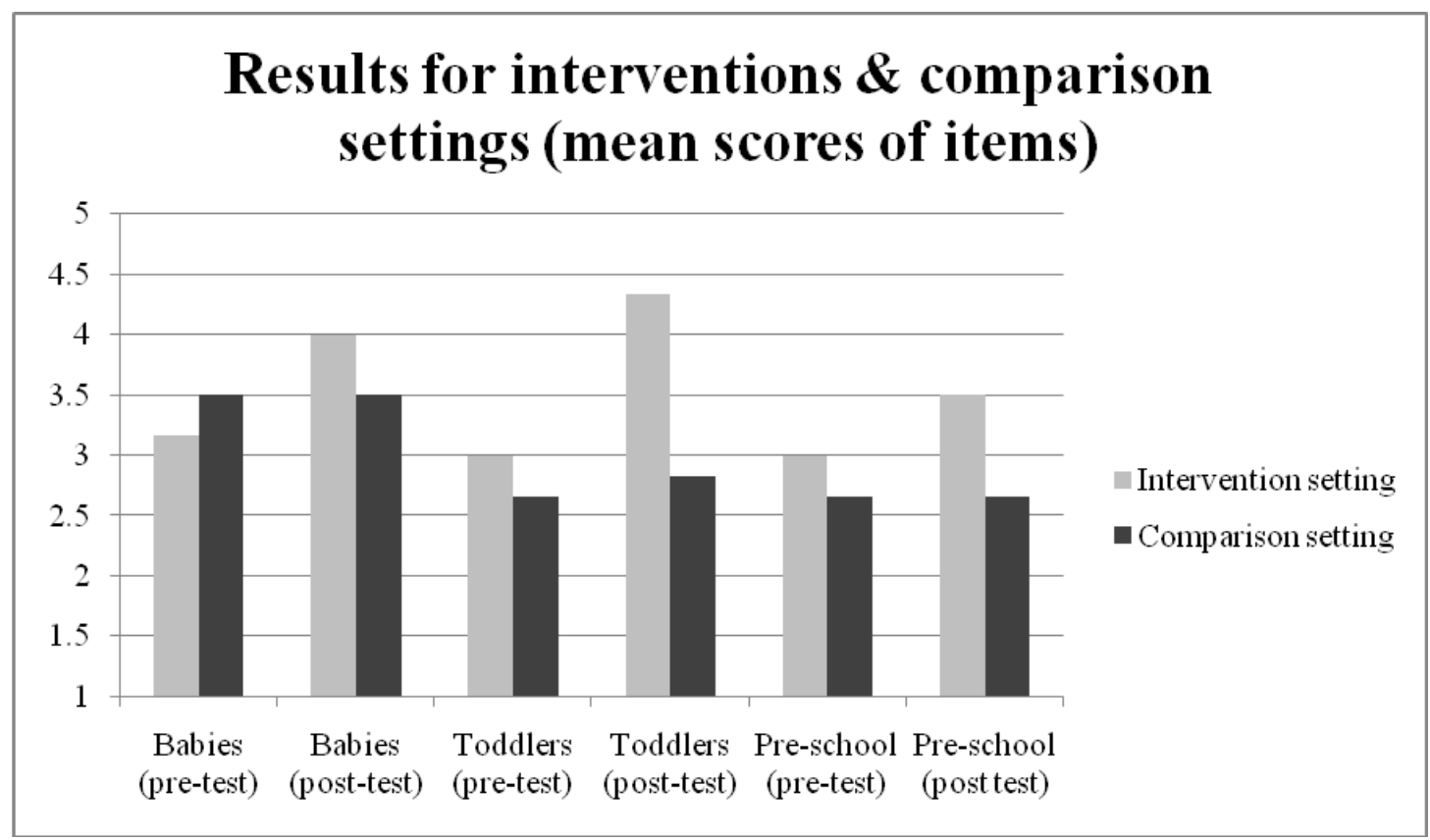

Score: 1 = inadequate; 3 = minimal; 5 = good; 7 = excellent

\section{Summary}

Quantitative data results illustrated in figure 1 above show that the intervention settings increased their scores significantly across the three items. Whilst scores for 
the comparison settings remained the same with the exception of a slight increase for the toddlers accounted for by additional resources.

Qualitative data gathered from unstructured interviews revealed that the manager found the rooms 'calmer' with staff 'enjoying their work a lot more' as they 'engage with the children'. The children's 'behaviour' was 'better because staff were playing with the children more' and the children were therefore 'responding to staff a lot more'. Parents had commented that the toddler room 'looks more appealing and fun'. The manager said there were 'benefits' for the two special needs children, as well as for all staff and children. Most adults were taking an active role with children in their movement-play and some made astute observations.

The findings of this small scale research illustrated that training and follow-up support made a difference to:

a) practitioner knowledge and understanding of movement-play

b) the adult role with practitioners adopting a Vygotskian interactive role

c) children sharing movement conversations with peers and adults

As a result children experienced improved movement experiences which would ultimately affect their learning and development (Lamont, 2007a; Goddard Blythe 2005).

\section{Discussion}

Mixed methods were employed in this study with the purpose of answering the research questions. The results were analysed before and after the intervention in order to make comparisons between the settings which received an intervention and those which did not.

The newly developed movement-play scale proved useful for assessing and improving quality over the period of the study. The results showed variations in results which 
indicate that this tool has some validity. Overall findings showed that an intervention did improve the quality of the environment and practice.

Significant improvement in quality reaching 'good' and above for space and resources were recorded for two rooms at intervention setting 2 otherwise there was no change in this item for other rooms. This can be accounted for by the lack of 'challenging activities outdoors' (indicator 5.3) which meant that scores stayed below 'good' in these rooms. In some instances outdoor equipment was not conducive to children undertaking vigorous and challenging activities.

A similar finding relates to item 3, planning for movement from observations of children, where the same two rooms showed increased scores but others stayed the same. Practitioners said that they found it difficult to plan for this area in their usual planning format which was limited by the design given to them by their managers. Some also felt unconfident about writing observations of children's movement activities. It is likely that the four week follow up did not allow sufficient time to support practitioners in this area.

Results indicated that the intervention had more consistent outcomes for adult engagement in movement with children across the study. Practitioners were willing to take a more active role with children post intervention when they were prepared to freely move with children, sometimes engaged in shared movement conversations. Improvement in the quality of the adult role led to children expanding their movement repertoire. Contrastingly, quality at both comparison settings remained at below minimal over the same period of time. This finding indicates therefore that the intervention did make a difference to the quality of adult engagement in movement with children. 
This suggests most adults adopted a Vygotskian interactive role becoming active agents in children developing their movement experience. For Vygotsky the adult role is critical to the quality of play and learning for the child (Siraj-Blatchford, 2009). This contrasted with adults tending to stand back observing children at the comparison settings.

Lack of adult intervention in children's physical activity was highlighted by Evangelou et al (2009) in the literature review with Maude (2006) bringing attention to the central role of the adult in cultivating children's physical literacy. Prior to the intervention in this study children appeared to be engaging in low levels of physical activity with limited or no intervention from adults.

Findings post intervention show that there was an increase in the variety of movement-play activities provided and in some cases children experienced more challenging and vigorous play. This suggests that an intervention results in improved movement experiences for children which the literature informs us should have an impact on their learning and development (Lamont, 2007a; Goddard Blythe, 2005)

\section{Conclusion}

The first five years in a child's life are critical for their social and language development and cognitive progress. Such developmental outcomes are found to be significantly related to the characteristics of quality in pre-school settings (Sylva et al 2006b). Influenced by the EPPE study the authors of this article developed a movement-play sub-scale specifically to assess quality in settings with children from birth to age five years.

This research used mixed methods in natural settings in order to discover if an appropriate and targeted intervention results in enhanced movement experiences for young children. Findings have shed light on the quality of the environment and 
practice at the settings involved in this small scale research. In this respect the study is valuable as it highlights the effects of an appropriate targeted intervention on children's movement experiences as well as measures of quality related to an intervention.

\section{Inter-disciplinary discussions}

This research informs practitioners about movement and its effects on the brain in young children. Teachers are keen to learn more about advances in neuroscience and how they affect classroom practice and this research is important for classroom practice. If we are to support children's development in the best possible way then teachers need to be included in any future inter-disciplinary discussions with neuroscientists and policy makers.

\section{Policy}

The inclusion of physical development in the prime areas of learning in the UK Early Years Foundation Stage is welcomed because reference to physical development by policy makers is often overlooked when assessing children, particularly those with special needs (Goddard Blythe 2005).

However, the government's focus on school readiness including reading tests for all six year olds is likely to pressurise teachers to take a more formal approach to teaching. Children engaged in more literacy tasks may consequently be seated in a sedentary position at their desks, indoors. While the government believes this is very positive, they have overlooked yet again the importance of both 'developmental and physical readiness for formal education’ (Goddard Blythe 2011, 1).

\section{Future research and implications}

There has been limited research on movement-play in the early years and there appears to be a paucity of research on measuring quality in this area therefore the 
value of this research lies in the contribution it thus seeks to make. In this respect, the development and use of this scale provides a valuable measure.

A further study might for example use a larger sample spread across different settings in the private, voluntary and maintained sectors. There is scope for a larger scale piece of research in order to further test the validity and reliability of the scale.

Acknowledgement We are very grateful to all the practitioners and the children at the settings who took part in the pilot and study. 


\section{References}

Belsky, J. 2001. Emanuel miller lecture—developmental risks (still) associated with early child care. Journal of Child Psychology and Psychiatry and Allied Disciplines, 42 (7) (2001), pp. 845-859

Blaise, M. 2010. “Designing to Scale: When Size Matters.” In Doing Early Childhood Research. International Perspectives on Theory \& Practice, 2nd ed., edited by G. Mac Naughton, S. A. Rolfe, and I. Siraj-Blatchford, 209-219. Berkshire: Open University Press.

Blakemore, S.J. and Frith, U. 2005. The learning brain: Lessons for education: a précis. Developmental Science, 8: 459-465. Available on: http://onlinelibrary.wiley.com/doi/10.1111/j.1467-7687.2005.00434.x/full British Educational Research Association (BERA). 2004. Accessed www.bera.ac.uk/publications/guides.php

Bruer, J.T. 1997. Education and the brain: A bridge too far. Educational Researcher, 26 (8): 4-16.

Bruer, J. T. 2002. “Avoiding the Paediatrician’s Error: How Neuroscientists can help Educators (and Themselves).” Nature Neuroscience 5: 1031-1033. Published online doi:10.1038/nn934

Cotman, C.W., Berchtold, N. C., Christie, L. A. 2007. Exercise builds brain health: key roles of growth factor cascades and inflammation. Trends in Neuroscience 30 (9): $464-72$ 
Dahlberg, G., Moss, P. and Pence, A. 1999. Beyond Quality in Early Childhood Education and Care. London: Falmer Press.

Evangelou, M., Sylva, K., Kyriacou, M., Wild, M., Glenny, G. (2009) Early Years Learning and Development, Literature Review. University of Oxford, Research Report No. DCSF-RR176

Goddard Blythe, S. 2005. 'Releasing Educational Potential Through Movement: A Summary of Individual Studies Carried Out Using the INPP Test Battery and Developmental Exercise Programme for use in Schools with Children with Special Needs.' Child Care in Practice, Vol 11, (4): 415 - 432.

Goddard Blythe, S. 2005a. The Well Balanced Child. Movement and early learning. Hawthorn Press. $2^{\text {nd }}$ Edition. Gloucesteshire: Hawthorne Press.

Goddard Blythe, S. 2007. Neurological Dysfunction as a Significant Factor in Children Diagnosed with Dyslexia. Symposium; Alternative Therapies. Paper provided personally by author.

Goddard Blythe, S. 2011. “Neuro-motor Maturity - an Indicator of Developmental Readiness for Education.” TAC Journal 4 (12).

Harms, T., Clifford, R., Cryer, D. 2005. Early Childhood Environmental Rating Scale Revised Edition (ECERS-R). New York, Teachers College Press 
Hillman, C.H., Erickson, K.I, and Kramer, A. F. (2008). Be Smart, Exercise Your Heart: Exercise Effects on Brain and Cognition. Nature Reviews Neuroscience, 9(1), $58-65$.

Howard-Jones, P. 2007. Transcript of the Keynote Seminar of the all-party parliamentary group on scientific research in learning and education.' Brain-science in the Classroom'. Attlee Suite, Portcullis House. The Institute for the Future of the mind. Available on http://susangreenfield.com/assets/Uploads/2007brainsciencetranscript.pdf

Lamont, B. 2007a. Learning and Movement. Available on: http://www.developmentalmovement.org/default.html

Lamont, B. 2007b. Babies Naturally. Available on:

http://www.developmentalmovement.org/default.html

Lamont, B. 2007c. Children Who Need Help. Available on:

http://www.developmentalmovement.org/default.html

Mathers, S., Linskey, F., Seddon, J., Sylva, K. 2007. Using quality rating scales for professional development: experiences from the UK. International Journal of Early Years Education, Vol. 15, No. 3: 261-274. 
Maude, P. 2006. How do I do this better? From movement development into physical literacy. In Teaching and Learning in the Early Years Ed. by D. Whitebread and P. Coltman 2008. $3^{\text {rd }}$ Edition. Published by Routledge, Oxon.

McCartney, K., Dearing, E., Taylor, B.A., Bub, K.L. 2007. Quality Child Care Supports the Achievement of Low-Income Children: Direct and Indirect Pathways Through Caregiving and the Home Environment. Journal of Applied Developmental Psychology, Vol. 28, Issue 5-6: 411-426

Munton, A. G., Mooney, A., \& Rowland, L. 1995. Deconstructing quality: A conceptual framework for the new paradigm in day care provision for the under eights. Early Child Development and Care, 114: 11-23.

O'Callaghan, R.M., Griffin, E.W., Kelly, Á.M. (2009) Long-term Treadmill Exposure Protects Against Age-Related Neurodegenerative Change in the Rat Hippocampus. Hippocampus. 19(10): 1019-1029. (Paper provided by author)

O’Callaghan, R.M., Ohle, R. and Kelly, Á.M. (2007) The effects of forced exercise on hippocampal plasticity in the rat: A comparison of LTP, spatial- and non-spatial learning. Behav Brain Res. 176(2): 362-6. (Paper provided by author)

Peisner-Feinberg, E.S., Burchinal, M.R., Clifford, R.M., Culkin, M.L., Howes, C., Kagan, S.L., Yazejian, N., Byler, P., Rustici, J., Zelazo, J. 2000. The children of the cost, quality, and outcomes study go to school: Technical report. Chapel Hill: 
University of North Carolina at Chapel Hill, Frank Porter Graham Child Development Center.

van Prag, H. (2009). Exercise and the brain: something to chew on. Trends in Neuroscience, 32(5): 283-290.

Robert-Holmes, G. 2011. Lecture at Institute of Education. Masters in Early Years Childhood Studies: Research Methods: Session 8, Questionnaires and Interviews

Robson, C. 2002. Real World Research (2nd Ed.) Blackwell Publishing, Singapore

Siraj-Blatchford, I. and Wong, Y. 1999. Defining and Evaluating ‘Quality’ Early Children Education in an International Context: Dilemmas and Possibilities. Early Years 20: 7-18.

Siraj-Blatchford, I., Sylva, K., Muttock, S., Gilden R., and Bell, D. 2002 Researching Effective Pedagogy in the Early Years, London: DFES Research Report 365.

Siraj-Blatchford, I. 2009. Conceptualising progression in the pedagogy of play and sustained shared thinking in early childhood education: A Vygotskian perspective. In Educational and Child Psychology Vol. 26 No. 2

Siraj-Blatchford, J. 2010. Surveys and questionnaires: An evaluative case study in. In Doing Early Childhood Research. International Perspectives on Theory \& Practice $2^{\text {nd }}$ edition: Berkshire, 233-238. Open University Press 
Sylva, K., E. Melhuish, P. Sammons, I. Siraj-Blatchford, and B. Taggart. 2004. The Effective Provision of Pre-school Education (EPPE) Project: Final Report: A Longitudinal Study Funded by the DfES 1997-2004. Institute of Education, Sylva, K., E. Melhuish, P. Sammons, I. Siraj-Blatchford, and B. Taggart. 2004. The Effective Provision of Pre-school Education (EPPE) Project: Final Report: A Longitudinal Study Funded by the DfES 1997-2004. Institute of Education, University of London/Department for Education and Skills/Sure Start.

Sylva, K., Siraj-Blatchford, I., Taggart, B. 2006a. Assessing Quality in the Early Years: Early Childhood Environmental Rating Scale - Extension (ECERS-E)Four curricular subscales. Revised edition. Stoke on Trent, Trentham Books.

Sylva, K., Siraj-Blatchford, I., Taggart, B., Sammons, P., Melhuish, E., Totsika, V. 2006b. Capturing quality in early childhood through environmental rating scales. Early Childhood Research Quarterly 21: 76-92. 
Movement-play scale Item 1: Space and Resources

\begin{tabular}{|c|c|c|c|c|c|c|}
\hline Inadequate 1 & 2 & Minimal 3 & 4 & Good 5 & 6 & Excellent 7 \\
\hline $\begin{array}{l}\text { 1.1 } \\
\text { Little opportunity for movement- } \\
\text { play experiences for children. } \\
1.2 \\
\text { Little space for children to } \\
\text { move. } \\
1.3 \\
\text { Routines dominate the day. } \\
\text { (It is important to read } \\
\text { notes for clarification } \\
\text { and questions } \\
\text { overleaf) }\end{array}$ & & $\begin{array}{l}\text { 3.1 } \\
\text { Children have access to some } \\
\text { floor space for movement } \\
\text { indoors. (a) } \\
3.2 \\
\text { Some resources are provided } \\
\text { that encourage children to } \\
\text { move in a variety of ways. (b) } \\
\text { 3.3 } \\
\text { Children have access each } \\
\text { day to movement outdoors. (c) }\end{array}$ & & $\begin{array}{l}5.1 \\
\text { Sufficient floor space is available } \\
\text { indoors for children to move in a } \\
\text { variety of ways such as tummy } \\
\text { time, crawling, rolling, spinning } \\
\text { and rough and tumble. (d) } \\
5.2 \\
\text { Space and resources are easily } \\
\text { accessible for children in the } \\
\text { group (for example, they are on } \\
\text { the same level and in the room; } \\
\text { no barriers for children with } \\
\text { disabilities). } \\
5.3 \\
\text { Many challenging activities must } \\
\text { be accessible outdoors for } \\
\text { children to engage in physically } \\
\text { demanding play. (e) }\end{array}$ & & $\begin{array}{l}7.1 \\
\text { The range of activities provided } \\
\text { together with the organisation of } \\
\text { the resources and environment } \\
\text { enable children to spontaneously } \\
\text { participate in movement } \\
\text { activities alone or with their } \\
\text { peers and adults. (f) } \\
7.2 \\
\text { There is a wide range of } \\
\text { equipment and resources easily } \\
\text { accessible for children to use } \\
\text { when they want to or need them, } \\
\text { indoors and outdoors. (g) }\end{array}$ \\
\hline
\end{tabular}




\section{Notes for clarification}

Movement-play scale Item 1: Space and resources

Please note: Safety in terms of appropriateness and condition of space and equipment applies to all the points below. Mats and cushioning surfaces must be available for free fall and rough and tumble activities indoors and outdoors. Equipment in all areas must be safe so that major causes of serious injury are minimised. Adults must join children in their play or be nearby to ensure babies and children are safe. Any activities with babies and children must be carried out with their consent.

Movement-play activities include babies being on their backs and tummies, pushing up with their hands whilst on their tummies, rolling over, crawling, and pulling themselves up. Later on children will climb, jump, balance, swing, run, spin until they fall over, hang upside down skip, push and pull heavy items, rough and tumble

(a) 'Some floor space' means approximately $25 \%$ of the floor space in the room indoors is available for movement indoors.

(b) 'Some resources' means that there are at least three different types of resources accessible to children from the following lists:

- for babies: pillows and soft mats in defined area, small soft balls, large body balls, lycra, chiffon scarves, tunnel, tumbling mats, carnival sticks, shallow spinning cone, baby gym with slide, stairs and tunnels.

- For babies and children who seem immobile or reluctant to engage in movement activities adults will need to at

- for toddlers and nursery age children: cardboard boxes, space blanket, tubes, pillows, small soft balls, large body balls, lycra, large cotton covered elastic, carnival sticks, ribbon sticks, chiffon scarves, tunnels, spinning cone, balancing equipment, nursery gym with slide, stairs and tunnel; and tumbling mats.

(c) 'Access to movement outdoors' means least one hour each day in a setting open for four hours a day and proportionally more for settings open for longer hours.

(d) 'Sufficient floor space' means that at least $50 \%$ of the floor space in the room indoors is available for movement activities.

(e) 'Many challenging activities' means that more than three of the following types of equipment are also accessible for at least half the children to use at once from the following:

- for babies: floor space for babies to be on their backs and tummies, tunnels to crawl through, shallow spinning cone, soft play shapes to climb and jump off, lycra material for rocking babies in, baby gym with stairs, slide and tunnel, adults can also swing babies in their arms, hold babies upside down)

- for toddlers and nursery age children: spinning cone, slide, swing, A-frames and ladders, trampoline, monkey bars, climbing walls, climbing frames, trees to climb, equipment to jump off, equipment for balancing, swinging, tug of war, climbing over and under adult bodies, rough and tumble, and wheel barrows and bricks.

- Stationary and portable equipment need to meet this standard. To give credit, these types of equipment need to be accessible for a substantial portion of the day.

(f) 'The range of activities' means there opportunities for babies and children to take part in 5 or more of the activities listed below (and space is available) so that:

- babies: can be on their backs and tummies on the floor and can roll, crawl, climb, slide, spin, jump, hang upside down, push and pull.

- toddlers and nursery age children: can run, jump, spin, roll, crawl, be on their tummies, hang, slide, balance, climb, skip, swing, rough and tumble and push and pull or carry heavy items.

(g) 'A wide range of equipment and resources' would include sufficient resources for children to be able to engage in the range of activities described above.

\section{Questions}

1. How often do children use the resources available to them?

2. Is there space available for movement indoors when the weather is bad? 
Movement-play scale Item 2: Adults engaging in movement with the children

\begin{tabular}{|c|c|c|c|c|c|c|}
\hline Inadequate 1 & 2 & Minimal 3 & $\overline{44}$ & Good 5 & 6 & Excellent 7 \\
\hline
\end{tabular}




\section{Notes for clarification}

\section{Movement-play scale Item 2: Adults engaging in movement with the children}

(a) 'Sometimes' means at least once a week.

(b) 'Regularly' means approximately $3-5$ times a week.

(c) 'Vigorous activities' include:-

- for babies: being tossed in the air, swinging babies in your arms, tummy time, crawling, rolling, climbing, holding babies upside down.

- tor toddlers and nursery age children: hanging from A-frames or monkey bars, spinning and falling, pulling, pushing and carrying heavy things, tug of war, climbing, jumping, and running.

(d) For example, at least two of the following are shared with parents/carers: movement play leaflet for parents; meeting with parents/carers to discuss movement play and the benefits for their children; the DVD 'Moving, Learning and Growing' to be shown at a parents meetings; displays and/or a portfolio of children engaged in movement activities explaining the benefits.

(e) This includes joining children in their movement, displaying photos of children's engagement in movement activities, making booklets with children about their movement activities.

(f) Parents are offered the DVD to take home on loan; parents take home a copy of the movement-play leaflet, parents are loaned resources to take home to use with their child/ren in movement activities, the ways their child/ren like to move at home and at the setting are discussed with the parents with a view to offering opportunities to develop their interests and schemas.

\section{Question}

1. How often do you do movement activities with the children?

2. Do you use music with movement activities? Do some children/adults use musical instruments as other children move and dance?

3. Have you held a parents meeting about movement play for either mothers or fathers and carers? 
Movement-play scale Item 3: Planning for movement-play from observations of the children

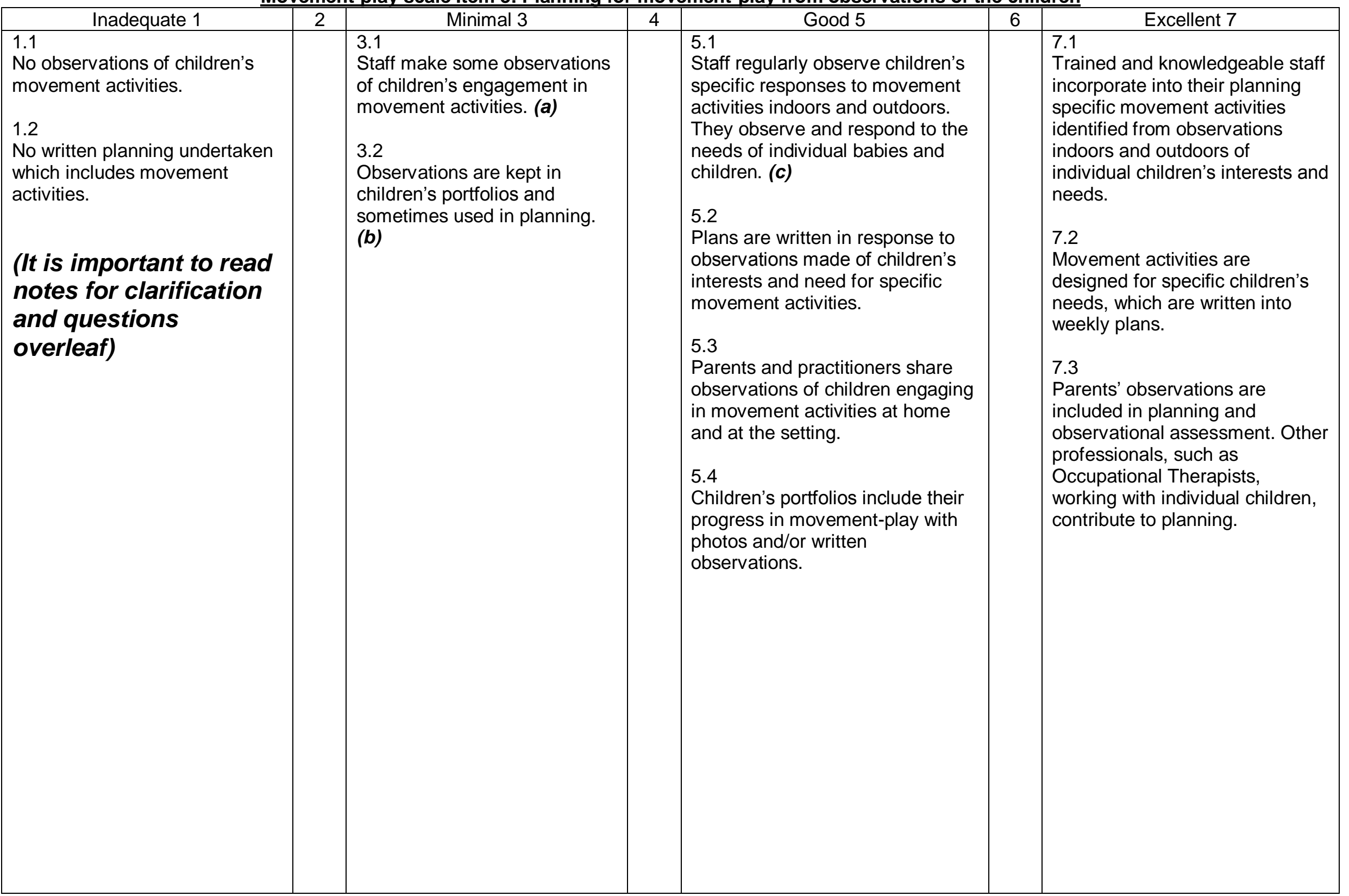




\section{Notes of clarification}

\section{Movement-play scale Item 3: Planning for movement-play from observations of the children}

(a) 'Some' means about once a month for at least one child.

(b) 'Sometimes' means at least once a week and written on the planning sheet.

(c) 'Regularly' means once a fortnight for babies and once a month for toddlers and nursery aged children, with a written record in the children's portfolios and on the planning sheets.

\section{Questions:}

1. How many members of staff have attended training in movement play?

2. Are movement activities written into your planning each week?

3. How often do you plan for movement activities for the whole group, small groups and individual children? 